\title{
Situational analysis of poverty and violence among children and youth with disabilities in the Americas - an agenda proposal
}

\author{
Análise da situação da pobreza e da violência entre crianças e jovens \\ com deficiência nas Américas - uma proposta de agenda
}

Fátima Gonçalves Caval cante ${ }^{1}$

Edward Goldson ${ }^{2}$

\footnotetext{
${ }^{1}$ Centro Latino-Americano

Abstract This article reviews the prevalence of poverty in Latin America and the Caribbean discussing the cycle and culture of poverty, their links to violenceand maltreatment among disabled children and youth, from 1990 to 2006. There is a discussion of child maltreatment both of typical and disabled children taking into consideration the disabled child's unique needs, the impact on the family and society and the availability of supports and resources. Finally, an agenda is set forth to address poverty and violence, seeking to diminish the prevalence of maltreatment of all children, but especially children with disabilities. In addition, there is the hope of breaking the cycle of poverty and supporting disabled and marginalized individuals. This agenda speaks to the need for multidisciplinary collaboration as well as collaboration regionally and locally among governmental and non-governmental agencies, advocacy groups and the community at large.

Key words Poverty, Disability, M altreatment among children, Political agenda, Cycle of poverty, Culture of poverty
Resumo Esseartigo revisa a prevalência da pobreza na América Latina e no Caribe, discute o ciclo e a cultura da pobreza e sua interface com a violência e os maus tratos contra crianças e jovens com deficiência, de 1990 a 2006. A discussão sobre os maus tratos focaliza crianças com e sem deficiência, levando em consideração a especificidade e necessidades singulares das crianças com deficiência, o impacto na família e na soci edade e a disponibilidade de suportee recursos. Finalmente, uma agenda éproposta para abordar o tema da pobreza e violência, ao procurar diminuir a prevalência de maus tratos entre todas as crianças, especialmente as crianças com de ficiência, ao quebrar o ciclo de pobreza e dar suporte para indivíduos com deficiência e marginalizados. Essa agenda aponta a necessidade de colaboração multidisciplinar, como também colaboração regional elocal entreorganizações governamentais enãogovernamentais, grupos de auto-ajuda e a comunidademaisampla.

Palavras-chave Pobreza, deficiência, M aus-tratos contra crianças, Agenda política, Ciclo da pobreza, Cultura da pobreza 
Introduction

The goal of this paper is to provide visibility to a triad of problems: poverty, disability and violence. These issues, when treated separately have not had the same impact on the public and among government officials and scientists as when considered together. The eradication of poverty is a millennium world goal which, in order to be achieved, depends on cooperation and exchange between nations, governments and international monetary funds. This paper will address these issues with a focus on the Americas, especially Latin American and the Caribbean. It is necessary to shed light on what seems to be an invisible problem: disabled people are the poorest of the poor and will remain at risk for increasing poverty, worse impairments and mental disorders and domestic or institutional violence, unless public policies, governmental and non-governmental agencies, advocacy groups, families and people with disabilities, empowered and better organized, do something. In this paper we are going to describe what has been recently done in the Americas about this triad of issues and what should be the agenda for the disability and mental health fields in order to better prevent poverty, disability and violence.

It is a privilege to introduce the issue 'poverty, disability and violence' in this article-debate with colleagues from the Americas, specially, United States, Colombia and Brazil. This international exchange is important for two reasons: (1) All people engaged in the article and in its debate, participated in the International Seminar: "Perspectives of facing the impacts of violence on public health: Latin America in focus" organized by Fiocruz Foundation/Ensp/Claves in Rio de Janeiro, Brazil in November, 2007; (2) This paper gave the authors the opportunity to share their efforts and studies, first by combining their accumulated experience acquired in practice and research in the disability field. Second, it provided the authors a way to present studies on maltreatment starting with the onewritten by Denver pediatrician C. Henry Kempe and his colleagues ${ }^{1}$, concerning the battered child syndrome (1962), and including theones from this decade 2 . Third, it provided the authors the opportunity to present the work developed with colleagues on the first Brazilian qualitative research ${ }^{3,4}$ addressing the combined issue of violence, disability and poverty (supported with grants from CNPq/M S/DECIT and FAPERJ 2005-2007). This work seeks to enhance human rights protection and violence prevention among children and youth with and without disabilities.
Poverty and inequality

in Latin America and Caribbean

According to data ${ }^{5}$ gathered during the 1990 s Latin America and the Caribbean (LAC) reduced poverty. Although the reduction was not uniform across countries (in a sample of 17 countries, 6 of them had poverty increased) theincidence of poverty decreased over 10 percent. However, the absolute number of poor people increased during the decade due to population growth. One third of the 180 to 220 million people in LAC, live in poverty according to data collected in $1995^{5}$ and in $2002^{6}$. M ost of them earn less than two dollars a day. Poverty is concentrated in households whose heads are employed in agriculture (35.5 percent) in rural areas, or in nonfinancial services ( 29.1 percent) in urban areas. Almost 44 percent of all children $(0$ to 17), compared to 27.7 percent for adults and 28.6 percent for elderly live in poor households. In urban settings poverty is higher among female heads of household ( 30.4 percent) than among their male counterparts ( 25 percent). Also, gender, ethnic and racial origins are also a feature of LAC poverty. In Bolivia, Brazil, Guatemala and Peru theincidence of poverty is twice as high for indigenous and afrodescendents, as compared to those of European descent ${ }^{5}$.

Studies of aggregate poverty and inequal ity estimates in LAC during 1970-19957,8 agreed with the description that poverty and inequality were reduced during the 1970s, according to welfare changes at the microeconomic level. These indicators deteriorated sharply during the 1980s, with different phases of growth or recession in each country. Given the favorable conditions observed in the first half of the 1990s, it was expected there would be a reduction in the number of poor and the level of inequality. Even though the 1990s was a decade of recovery and stability, poverty and inequality have not declined significantly in the region ${ }^{7,8}$. The gains in social indicators observed at the end of the decade were a modest reduction in poverty with progress in primary education and gender equity in school enrollments. However, there was less progress in reducing infant mortality, expanding the potable water supply, and controlling HIV/AIDS and other infectious diseases. It is important to note that progress has not been uniform across all countries in the region, since high achieving countries experienced reduction in infant mortality rates and haveimmunization rates of almost 100 percent 5 .

Disparities in human capital, social conditions and living standards between regions within coun- 
tries makeLAC themost inequitablein theworld ${ }^{5,7-}$ ${ }^{9}$. In thelate 1990s, the wealthiest 20 percent of the population received 60 percent of theincome, while the poorest 20 percent received only 3 percent. The gap between the poorest and richest segments of the population has widened in the past three decades $^{5,7}$. In most countries in equality is higher than expected according to per capita income. Inequalities are also associated with huge inequities in the distribution of resources like education, health, land and credit. Children of the poor have more disadvantages ( higher child mortality rates, greater school dropout rates, higher youth unemployment) than children of the wealthy. In Brazil, for instance, by 18 years of age only 15.2 percent of children among the wealthy had developmental problems while these problems occurred in 64.3 percent of poor children 5 .

Social exclusion is another problem, which is both a cause and effect of inequality. Socially excluded populations from LAC differed by gender, age, race, ethnicity, immigration status, HIV/AIDS, mental health disordersand disabilities. They share poverty, suffer multiple and cumulative disadvantages, stigma and discrimination. Persistent educational gaps between rich and poor are the key in explaining income inequality ${ }^{5,7-9}$. The schooling completion rates are 4 years for the poorest 20 percent and 10 years for the richest 20 percent ${ }^{5}$. Differences in the number of school years significantly affect income. Those with a primary school education have an income 18 percent higher than those having no schooling. A secondary school education yields returns of 61 percent and higher education yields returns of 152 percent ${ }^{10}$. The poor distribution of health, physical capital, including land, credit and infrastructure (energy, water and transportation), lack of employment opportunity, informal services are combined factors related to social exclusion and inequality. The author $\mathrm{s}^{5,6-9,11}$ concluded that the lack of progress in poverty reduction in the 1990s is due to the persistently high levels of inequality of education leading to economic and social disadvantages.

Considering that poverty and inequality are the most important problems to be faced in the world nowadays, in 1996 the United Nations De velopment Programm (UNDP) started a global initiative to assist poor governments in organizing national and local Poverty Reduction Strategies (PRSs). In 1999 this step was followed by the International Monetary Fund (IM F) and the World Bank. In the LAC region, the Inter-American Development Bank joined IM F, World Bank and other agenciesin supporting regional countries. ThePRSs serve to identify priorities, to elaborate policy reforms and key strategies for long-term poverty reduction goals, using indicators to measure their progress. Four Latin American countries are participating and have completed PRSs: Bolivia, Guyana, H onduras and N icaragua. Some countries of the region have implemented other types of integrated approaches for poverty reduction: Brazil, $M$ exico and Chile created new instruments to face poverty. Brazil and M exico are addressing individuals at all stages of the life cycle: prenatal, infancy, adolescence and youth, adulthood and old age. Chile's program combines assistance and the effort to empower and bring social integration to families living in extreme poverty in four areas: income (jobs), human capital (education, health, training and housing), social capital (social network) and vulnerability (by prevention). LAC countries and international agenciesareusing multiple fronts to face poverty and inequality ${ }^{5,9}$. According to Bouillon \& Buvinic ${ }^{5}$ investments in the human capital of the poor should be a chief priority in the policy agenda and in the allocation of public resources, and should be promoted through reforms that increase quality and coverage of basic social services.

\section{Poverty and disability in the world}

According to the report Understanding Inclusion of the First Inter-American Forum on Poverty and Disability in the Americas that took place in $M$ anagua, Nicaragua in August, 2004 (with 13 countries from LAC) ${ }^{12}$, the links between poverty and disability - that poverty causes disability and disability causes poverty-, has not yet been addressed. One of the barriers to addressing this issue is related to definitions of poverty. The way one thinks about poverty affects what one measures, and what one tries to change. Instead of thinking of poverty only from a monetary perspective, newer definitions focus on capability, social exclusion and participatory behavior $6,11-15$.

Poverty is a multidimensional phenomenon related to the lack of material supplies and varying inequalities, each one coming together, influencing each other through iniquities in school completion, access to health care and employment, among others $^{6,14}$. Instead of thinking of poverty only as lines of poverty, Costa \& Carneiro ${ }^{14}$ suggested one consider the different dimensions of poverty. In other words, consider multipleprivations, including nonmaterial privations, especially in chronic poverty. One should consider the attitudes, values, behav- 
iors among the very poor and the limits of their capability in the use of public resources and services. The authors ${ }^{14}$ use the term privation of capabilities as a way of linking poverty to social exclusion, both being described as the reflection of several vulnerabilities, which have to be seen more as a process, than as a stable condition. So, in considering strategies to reduce poverty it is necessary to consider the relationship between a number of variables: the dimensions of education, health, the nature of the household and income. Since exclusion is related to distinct situations, poverty reduction programs should be flexible, should strive for empowerment and social networking. In order to accomplish these tasks efforts from international and national financial agencies, governmental and nongovernmental organizations, privateand public institutions, families, communities and representative groups need to becoordinated. Only with societal efforts and commitments, especially with the participation of poor people, who understand and appreciate more clearly their day-to-day problem, will it be possible to face the major problem of the millennium: poverty.

In 2000 the United Nations adopted the M illennium Development Goals to consolidate efforts to reduce poverty in the World. These goals include:

1. Eradicate extreme poverty and hunger; 2 . Achieve universal primary education; 3 . Promote gender equality and empower woman; 4 . Reducechild mortality: 5. Improve maternal health; 6 . Combat HIV/AIDS, malaria and other diseases; 7 . Ensure environmental sustainability; 8 . Develop a global partnership for development ${ }^{12}$.

In both wealthy and poor countries, peoplewith disability and their families pay an economic, social and political price. Excluded from education, they have less opportunity to earn a decent living, mothers or caretakers have to sacrifice work or education. In addition, there is the extra cost of medicine, health care, special diet, and adapted transportation. Families are marginalized, isolated and stigmatized. There is a lack of time and energy to build social networks or to engage in political activities, and little opportunity to influence the policies that affect them. Why are people with disability and mental health care needs the poorest of the poor? The answer is simple: there has been no attempt or an investment of political will to translate their legal rights under thelaw into reality. As long as the design of poverty reduction strategies is still related to traditional economic measures, as the criteria to allocate resources, than people with disabilities, and their families, will re main among the poorest of the poor ${ }^{12}$.
According to Wolfensohn ${ }^{13}$ until recently disabled persons werenearly "invisible" in Poverty Reduction Strategy Papers (PRSPs). In 2003, the issue of disability became more prominent, especially among Eastern European Countries. The author ${ }^{13}$ reviewed a total of 33 PRSPs, selected from 2000 to 2004. $\mathrm{H}$ is purpose was to review the disability policy content of PRSPs. The PRSPs were introduced in late 1999 as a key instrument for H eavily Indebted Poor Countries (HIPC). Since them, 38 PRSPs havebeen prepared, most arefound in Africa (twenty), others in Asia, seven in Eastern Europe and four in Latin America. Thisstudy concluded that 73 percent of PRSPs recognized that disabled people live in the poorest households and are at risk for experiencingsignificant poverty. However, few PRSPs described the poverty risks faced by disabled persons and the mechanism exclusions. Only 23 percent mentioned the exclusion and stigma faced by disabled persons, but even in these cases there is no recognition of the cumulative nature of disabilities. Strong emphasis was given to early childhood interventions ( 90 percent of PRPS), but only a minority included specific rehabilitation measures (43 percent) and there is a lack of attention given to mental health disorders, alcohol and drug use.

The size of the disabled population remains a controversy, depending on the definitions of disabilities. Some countries' population census suggested 2 to 3 percent of population suffer from most extreme forms of disabilities. Other countries with broader definitions of disabilities have reported a much higher rate of disability, 15 to 20 percent of the population $^{12,13}$. According to the World Health Organization ${ }^{16}$, disabled people account for 10 percent of the population worldwide.

\section{The impact of poverty on quality of life}

Disabled peopleareaffected by discrimination, social exclusion and stigma. If left unaddressed, the cumulative effect of these experiences translates over time into a combination of exclusions that result in social disabilitiesand poverty. To comprehend the impact of poverty on life, we need to answer two questions: How do initial impairments results in social disabilities and poverty later on in life? What does it mean to live in the dual real $m$ of poverty and disability?

A World Bank study revealed that half a billion disabled peopleareamong the poorest of the poor ${ }^{17}$ and are estimated to be 15 to $20 \%$ of the poorest in developing countries ${ }^{18}$. According to U NICEF, less than 3 percent of disabled children are enrolled in schools and most disabled adults are excluded 
from productive employment ${ }^{13}$. Although in the countries of the LAC there are limited statistics about the impact of poverty and disability, data from governments, international agencies and nongovernmental organizations ${ }^{12}$ point out that poverty and disability influence each other and often co-occur.

Sinceit is observed ${ }^{17,18}$ and expected ${ }^{12}$ that there is a high rate of chronic poverty among disabled people, it is important to point out that not all disabled people are poor, in economic terms. However, under conditions of chronic poverty, social exclusion is a major issue, due to lower expectations, lack of resources, poor health and poor education. Social exclusion, more than poverty, is experienced in a broader way for most disabled people, due to the vulnerability related to social status, stigma, privilege, race and gender.

$M$ any disabled children do not survive, particularly those born in poor communities. The ones who survive grow up excluded from formal and informal education, which affects their ability to earn a living, and their level of confidenceand selfesteem. The consequence is that later they will have restricted employment opportunities due to inadequate or a lack of an education, discrimination, isolation, a lack of experience and confidence. Excluded from social, economic and political opportunities, disabled people fall further into chronic poverty and have little opportunity to break the cycle of disability-poverty (Figure 1). On the other hand, severe poverty increases the risk of being impaired. Life in chronic poverty limits the access to land, shelter, healthy food, healthcare, education, employment, and offers hazardous working conditions ${ }^{19}$. These cumulative factors can cause illness and impairments, leading to more marginalization and exclusion, resulting in disability that emerges as a cycle of poverty-disability (Figure 1 ).

A strong emphasis on quality of life of people with disabilities has been prevalent over the past two decades ${ }^{20-22}$. This concept emerged as a useful indicator of outcomes of policy initiatives ${ }^{23}$. According to Park, Turnbull \& Turnbull III ${ }^{20}$ quality of life experienced at thefamily level can be defined as the way family members have their needs met, enjoy their life together as a family and have opportunities to pursueand achieve goals that are meaningful to them. The authors pointed out, as an international agreement among research teams, that there is no standard family quality of life and each family decides what "quality" means to them. Between the tension of 'social parameters' for policies and 'family's life perception', the authors proposed five domains with which to examinetheimpact of poverty on family quality of life: physical environment, health, emotional wellbeing, productivity and family interaction. We included education among the others, as you can see in Figure 2.

The six domains are defined as: (1) Impacts on physical environment - home environment and neighborhood environment which include land, shelter, infrastructure (energy, water, transportation, housing supplies) and social network within the community; (2) Impacts on health - family's heal th status, health careand half impact, especially related to hunger, under-nutrition during pregnancy and limited access to health care; (3) Impacts on emotional well-being - the emotional aspects of family quality of life related to stress and adaptability (feelings, anxiety, mental health problems and coping strategies); and self-esteem (the degree to which theindividual evaluates his or her own worth); (4) Impacts on education - cognitive development and schooling, social and life skills, academic and language stimulation, extra-curricular activities (sport, arts, leisureand recreation, cultural events); (5) Impacts on productivity - useful activity which helps to develop working skills, training of specific competences, participation in meaningful social and cultural activities, jobs opportunities, personal accomplishments; (6) I mpacts of family interaction conscious and unconscious components of family life, routines, relationship among family members, roles, emotional climate, communication, behavior and forms of discipline, with special focus to the parent-child interaction (sense of security and trust) and other family interactions (the way they lead to pressure, conflicts, frustration, gain satisfaction, enhance adaptability to the member with a disability).

Since poverty permeates several domains of a family's qual ity of lifeno single profession or agency can meet the multifaceted needs of poor children and their families alone ${ }^{20}$. It is necessary to establish school-family-community partnerships as we will detail later. A third factor associated with chronic poverty and disability is going to be presented now, by addressing the link between disability and violence.

\section{Violence \\ against disabled children in the Americas}

One of the characteristics of the $20^{\text {th }}$ and $21^{\text {ts }}$ centuries has been the persistence of violence among nations and individuals. It is clear that violence, in all of its forms, is destructive to human life and to the well-being of mankind. Moreover, it is most 
Cycle of Disability-Poverty

Disability Discrimination

Disability

Additional Impairment

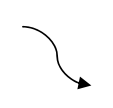

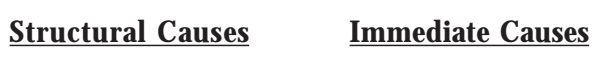

Social Exclusion Social Isolation Low Expectations Limited Resources Lack of Support

Fewer skills
Low Self-Esteem
Lack of ability
Poor health
Poor education

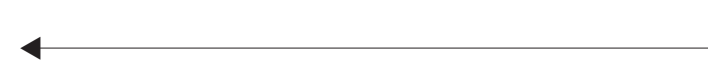

Cycle of Poverty-Disability
Reduced income/ Less opportunities

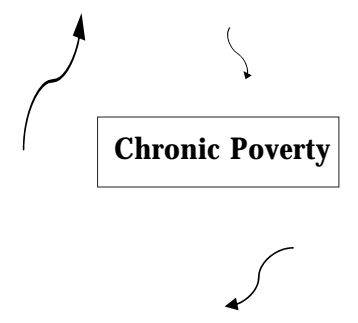

Increased risk of illness

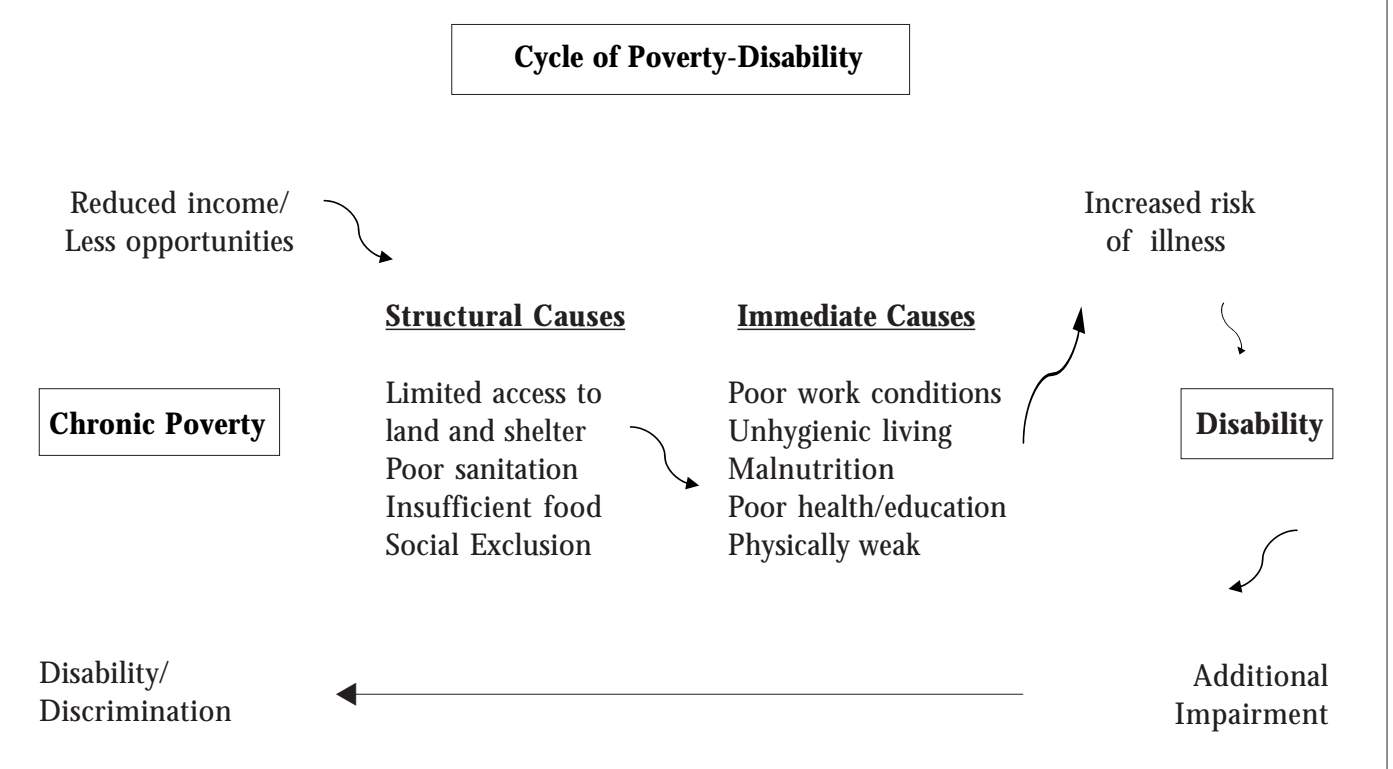

Figure 1. Cycle of disability-poverty.

Source: Richler ${ }^{12}$, Wolfensohn ${ }^{13}$, Yeo ${ }^{19}$.

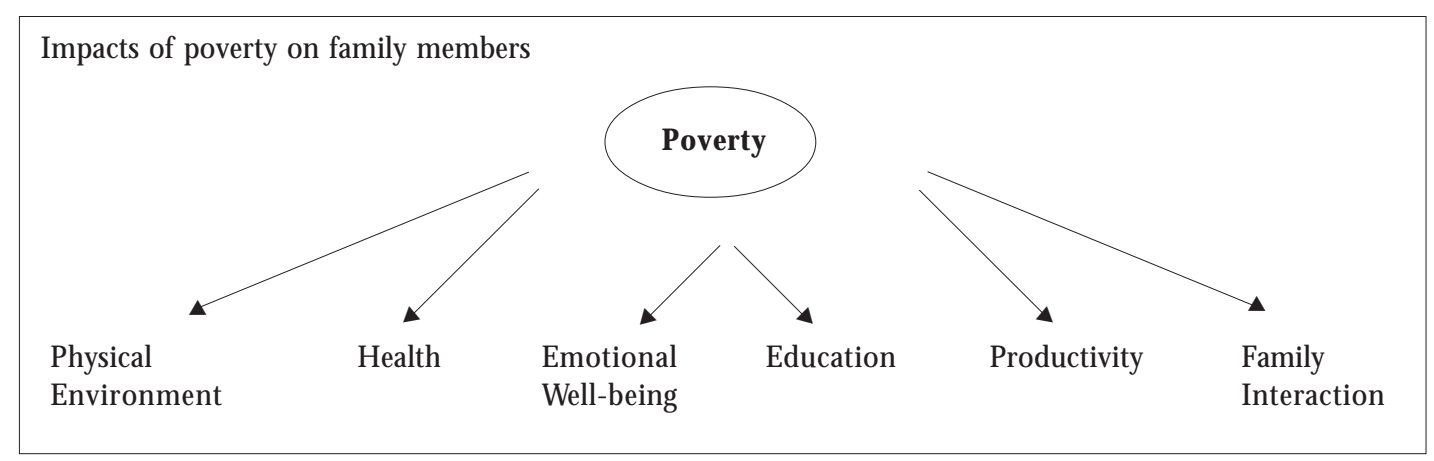

Figure 2. Impacts of poverty on family members.

Source: Park, Turnbull, Turnbull III ${ }^{20}$. 
destructive to those members of society who are dependent on the support of those responsible for their care, love, guidance and protection, namely children and youth and, more specifically, individuals with disabilities or special health care needs. Considering a more focal and local perspective, violence has been an integral and dominant factor in the history and political and social life of Latin America which, unfortunately, continues to be so. Latin America is one of the most violent regions of the world. Interpersonal violence was the fifth most important cause of death in thetotal population in LAC in $2002^{6}$.

$M$ altreatment of children is widespread around the world and has been so for generations. As one attempts to address the issue of maltreatment it is important to have clear definitions of this phenomenon. Below are cited two definitions (or descriptions) from the United States: (a) Child maltreatment means the physical or mental injury, sexual abuse or exploitation, negligent treatment, or maltreatment of a child by a person who is responsiblefor the child's welfare under circumstances which indicate harm or threatened harm to the child's health or welfare ${ }^{24}$; (b) Child maltreatment means "Any interaction or lack of interaction between a child and his or her caregiver which results in non-accidental harm to the child's physical or developmental state" 25 .

Thefirst definition is a legal oneand is embodied in the United States Code. The second definition is a pediatric definition. Thesedefinitionsaredifferent in origin, yet very similar in content despite the differencesin thewording. Thelegal definition forms part of the foundation for all reporting acts in the United States, which are part of the laws in all 50 states in union. The pediatric definition by Dr. Ray Helfer, articulates the relationship or lack of relationship that can be destructive to the child's physical and developmental well-being. At thesametime, it should be noted that "child maltreatment" is an umbrella term under which are subsumed several subtypes of maltreatment including non-accidental trauma, neglect, sexual abuse, physical and psychological abuse.

In the United States, as reported through the $\mathrm{N}$ ational Center on Child Abuse and Neglect (NCAND) in 2004, therewere $1,860,070$ reports of suspected abuse from 49 states and the District of Columbia. From this group 477, 755, which represents $25.7 \%$ of theinitial reports, were substantiated through legal processes ${ }^{26}$. In reviewing the percentage of each form of abuse, $62.4 \%$ involved neglect, $2.1 \%$ involved medical neglect, $17.5 \%$ were the result of physical abuse, $9.7 \%$ of the children were sexually abused, $7 \%$ experienced emotional or psychological abuse and $14.5 \%$ involved some other form of abuse such as abandonment. Although, it is frequently otherwise believed, child maltreatment is a family affair, which involves all social, ethnic, racial and socioeconomic groups. The most frequent perpetrators (78.5\%) are parents with an additional $6.5 \%$ being other relatives and $4.1 \%$ unmarried partners. The remainder of the perpetrators is foster parents, day care providers and others. Bye and large, children are not abused by strangers. Onethousand four and ninety of these children died as a result of their abuse in 2004.

The more specific focus of this paper is violence and maltreatment among children with developmental disabilities (DD). Children with disabilities are a subgroup of the population of children with special health care needs (CSHCN). This group is of importance in that it represents a significant population of children in theUnited States. It is defined as follows: "children who have or are at risk for a chronic physical, developmental, be havioral, or emotional condition and who also require health related services of a type or amount beyond that required by children generally"27. This then defines the overall population of children to be addressed in this paper. Finally, there are data concerning the incidence of maltreatment among children with disability (a subset of CSHCN) reported by NCAND in 2004. With respect to this population the data are incomplete but 36 states reported 559,410 victims of maltreatment. Of this number 41, 083 (7.3\%) had a disability. This suggests that this is a population at increased risk for being maltreated. This reflects the statein theUnited States.

In LAC, we have data on childhood mortality. In Costa Rica, there is a death rate of 13.7 children per thousand before one year of age. In $\mathrm{H}$ aiti, the rateis 86.2/1000, in Bolivia to 75.1, in Brazil to 57.7 and in Peru to 55.5. Unfortunately, this public health indicator has not decreased in LAC, as expected during the $1990 \mathrm{~s}^{9}$. Several indicators reveal a process of family weakness. There is an increase in the number of families with women heads of household, poor and alone (more than 20 percent). Be tween 30 to 50 percent of women suffer psychological violence at home, and 10 to 35 percent suffer physical abuse ${ }^{28}$. In the region there are more than 17 million children who work, according to International Work Organization'. It is observed as well that thereisa growth in juveniledelinquency and in thenumber of street children ${ }^{29}$. Unfortunately, there are very limited, if any, data gathered in a reliable and organized manner documenting specifically maltreatment among children with disabilities em- 
anating from LAC or countries like Brazil, Bolivia among others. Reporting systems designed to identify abuse and protect the victims are poorly organized. It is necessary to confront the lack of information on the issues of poverty, disability and maltreatment by establishing a better system of information gathering which should be one priority of a public agenda, thereby addressing this problem directly and making it more visible.

\section{Child, family and society}

O ne of the central issues that need to be addressed is why are children with disabilities seemingly so vulnerable to abuse? This is the case in the United States and seems to be so in Brazil, Colombia, Peru and other countries from LAC. One way of framing the question is to look at the three participants, or stake-holders: the child, family and society and think of them as forming a ven diagram. Each brings a unique constellation of characteristics, challenges, needs and expectations that interact with one another and can lead to maltreatment, or possibly to more positive relationships and outcomes.

Let us consider the child with a disability first. By way of generalizing one can accept that many children with disabilities havesignificant behavioral problems that are difficult to manage, are manifested under circumstances that are challenging and/or embarrassing for the caretaker (i.e. acting out in public or having school difficulties) and create considerable distress and embarrassment for the family. In addition, children with developmental disabilities (DD) frequently do not meet their parents' expectations, particularly those who appear "typical" but do not behave in a typical or acceptablemanner. This createstension, stress, frustration and anger among caretakers. For children with DD with more complex medical and physical problems their care is physically demanding, timeconsuming and costly. These children are irritable, their careis unremitting, they do not recover or 'get well,' respite care is frequently unavailable which places enormous stress on the entire family including siblings. In addition, both in the United States and LAC, there are limited resources for care and education of these children which, even when they are available, are very costly and otherwisefrequently difficult to access leaving the family with limited supports and guidance. Fatigue, frustration, financial and emotional stress, unremitting care, no respite and limited resources and poverty arethe conditions under which many families with children with DD live. Parents "burn out!"
The second component of the diagram is the caretakers, usually the parents. Frequently, as a result of the disability and the family's response to the disability, they become socially isolated, rejected and marginalized. Unless they can become involved with other parents with children with DD who can providesupport, their lives are constrained and limited. These conditions interface with family dysfunction, not infrequently associated with caretaker immaturity and limited access to formal and informal supports. Furthermore, caretakers of children with DD may have their own psychopathology, which compromises their ability to be effective caretakers. What often also takes place is parental denial of the disability leading to poor utilization of resources even if they areavailable. In addition, the establishment and maintenance of a parent-child relationship that is nurturing and interactive is compromised and often disrupted. Finally, and of great significance, is parental sense of guilt, inadequacy, a sense of having no control and being overwhelmed by the multiple demands placed on them by the child and his/her needs, inadequate financial resources inadequate services and unresponsive systems.

The third component of the diagram is the community/society. First, I would suggest that United States, like LAC culture, values "self-reliance," an able body and a "can do" attitude. By and large these societies take a dim view of individuals who are "different" and not in the mainstream. The vulnerability of disabled children stems from their experience of having disabilities in a society which puts value on being non-disabled ("ablebodied") and which discriminates against disabled people $e^{30}$. In addition, both the United States and LAC are violent societies. We live in cultures that allow and encourage the use of violence to resolve conflict, deal with frustration and stress and address differences and unmet expectations. We tend not to use mediation and non-violence to address these issues, which are frequently associated with disability and made more complex by the presence of poverty and inadequate systems and supports.

It is also of significance that society has many misconceptions of the disabled and some distinct prejudices. There is the belief that the disabled do not feel pain like typical individuals. The disabled do not havethe same needs and feelings and desires and the capacity to be loved and to love as do nondisabled individuals. As a result of the "less than human condition" they are not entitled to the same rights and consideration as are able-bodied children. Resnick in a 1984 paper articulates these perceptions, some of which may have changed in the 
last 24 years, but I would hazard to say still persist. In a study of professional staff views of individuals with disabilities he noted a hierarchy of acceptability. The least acceptablewere those individuals with mental retardation, syndromes and cerebral palsy. M edium acceptability were those individuals with blindness, deafness, speech deficits, seizures, and by implication those with learning disabilities and psychiatric disorders. The most acceptable among the disabled were those with amputations, those who were wheel-chair bound, thosewith chronicillnesses but all of whom were intellectually competent ${ }^{31}$. Resnick also described the "sociological destiny for the disabled" which included lower educational attainment, a greater incidence of non-employment and lower wages when they are employed, a lack of upward mobility resulting in poverty. In addition, the disabled tend to be more socially isolated and have fewer social contact, havemoremedical problems and "they don't get well" ${ }^{31}$. Finally, by way of summary Resnick states, To be a help person in this cultures which values self-relianceand independence, includes subtle yet pervasive expectations in terms of dependency and gratitude. The ramifications of such a social identity are enormous"31 (Figure 3).

One of the questions that emerges, as one considers maltreatment among the DD population, is whether there are particular groups that are more vulnerable than others. In the past, sexual abuse was reported more commonly among institutionalized individual $\mathrm{s}^{32}$. Ones sense is that this has changed as many institutions have closed in the United States. This is also the case in Brazil as an example of the effect of the deinstitutionalization process, especially in mental health field related to theBrazilian Psychiatry Reform within thelast two decades. It should be noted however, that from the accumulated data that it is not necessarily the most profoundly disabled but rather those who may be higher functioning, who have significant behavioral problems and who do not meet their caretaker's expectation (parents, teachers) who are at greatest risk for maltreatment.

Finally, among the key issues for children with disabilities is the prevention of maltreatment. This needs to take place within existing cultural contexts, which will not bealtered immediately although strategies for change should be considered. One could arguethat early identification of impairment and disability would be critical in preventing maltreatment as one would hope these children and their families would be directed toward systems and programs designed to support, educate, and nurture. These programs could beestablished and/ or expanded even within an environment conduciveto violence.

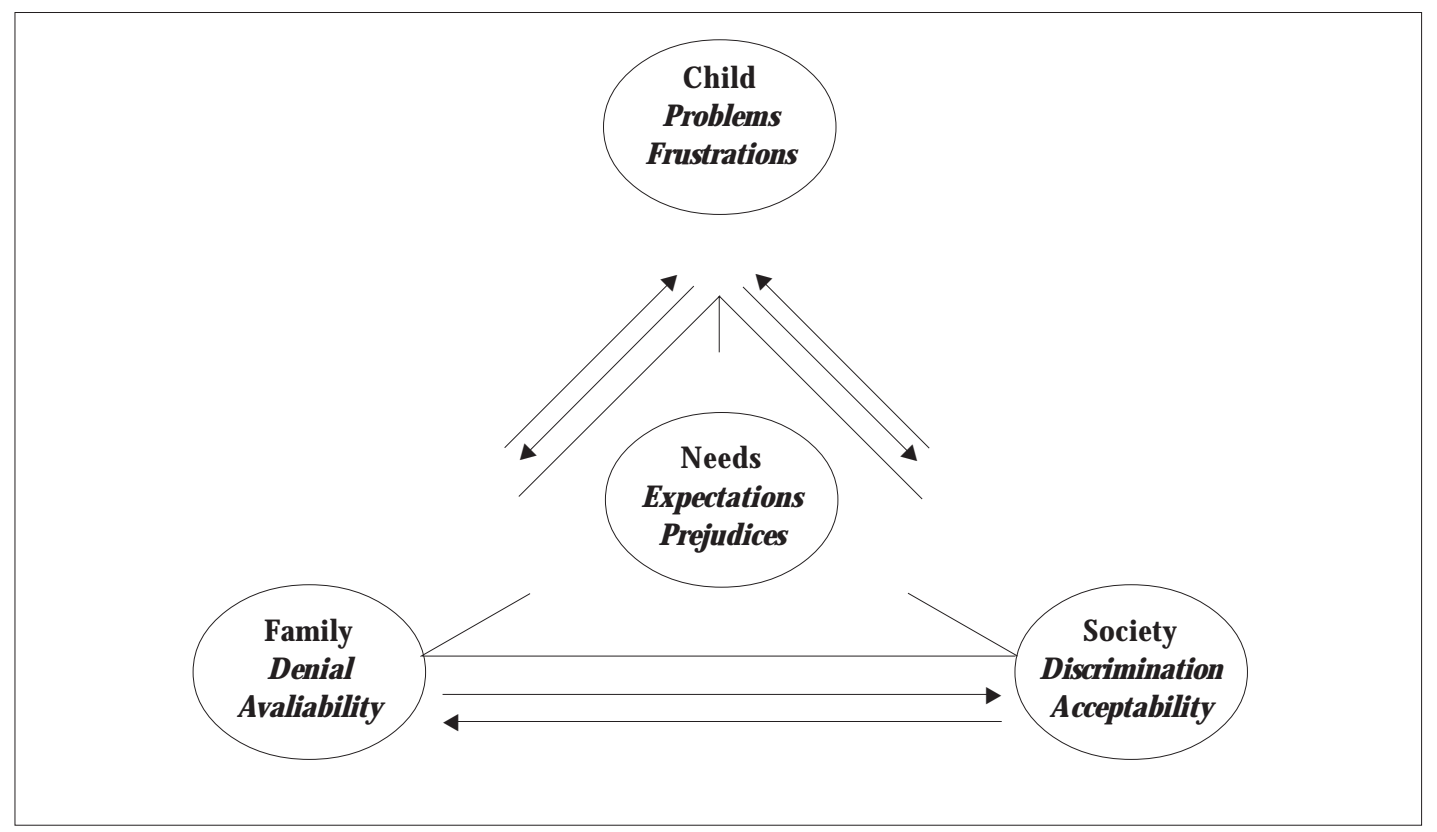

Figure 3. Child disability development within family and society. 
Poverty, disability and violence

It is important that we recognize that not all disabled people are poor, and that not all poor have impairments, disabilities or mental health disorders, and we acknowledge that violence does not occur only within the context of poverty. Violence occurs in all societies, it involves the rich and poor, all ages, and is world wide in the history of humanity. Although, the focus of this paper is to understand the risk conditions, which exist when there is poverty, the broader issue to be considered is the factors associated with the profound inequalities associated with poverty. One needs to consider the levels of poverty, especially chronic poverty, and how it affects peoples' qual ity of life and is related to impairments, leading to disabilities or mental health disorders, or to maltreatment. We know that many poor people do not have developmental disabilities, do not respond with violence to stress and frustration because they have good coping skills or resilience strategies to deal with poverty and disability. At the same time we need to focus on structural causes (social exclusion, limited resources, low expectations, social isolation, lack of support) that interact with the personal and immediate causes (level of health, education, skills, abilities, self-esteem) that produce multiple privations. Different dimensions of poverty, related to education, health, shelter, environmental infra-structure, employment conditions, income, emotional well-being, among others, interact with each other producing different privations of that negatively affect peoplein an intergenerational way. The lack of material resources and poor social conditions is associated with negative attitudes, values, ways of behaving and reflect a culture of poverty.

Intense social vulnerability is frequently associated with low expectations, poor self-esteem, resignation, resentment of the more financially and socially advantaged. Social exclusion is central to understanding a culture of poverty. Buchardt, Le Grand, Piachaud, according to Costa \& Carneiro ${ }^{14}$, analyzed the evolution of the social exclusion concept and defined it in three ways: (1) to designate those who are outside of the margins of the social protection system, without access to protectivenets (concept from France); (2) the presence of an underclass, the social marginalization of people with personal, values and behavioral characteristics related to the social production of the marginalization culture (concept from USA); (3) groups who are lacking basic rights and have difficulty accessing these rights (concept from international organizations). The three concepts are interesting as they identify and articulate the various aspects of this multidimensional problem. Poverty and social exclusion challenge public polices to deal with a multiplicity of inequalities, not thinking only in terms of class divisions, with one-dimensional and linear polarization, but as phenomena that should be seen much more as a process related to interactive factors and shifting conditions ${ }^{14}$. From a public policy perspective it is necessary to invest in education, health, poverty and inequality reduction programs, in order to changethe culture of poverty. This is the broad-based approach necessary to addressing those factors inherent in this culture that lead to human privation, to diminishing theindividual and his/her capabilities leading to the generational perpetuation of a culture of poverty.

The use of the term new morbidity has been introduced into theliterature to describethe association between childhood disability and family structure (single-parents are at major risk); poverty; and ethnic, linguistic and cultural status ${ }^{20}$. "The term also suggests a multipronged approach to addressing the challenges of family quality of life that are related to poverty". Individuals with disabilities are profoundly affected when their quality of lifeis compromised, especially when there is lack of healthy living conditions and socio-cultural deprivation. Exclusion is one of the greatest challenges faced by persons with disabilities and their families because it contributes to iniquity and isolation. Living a dual real $m$ of disability and poverty exacerbates the multiple privations that lead to more severe impairments and inequalities, perpetuating the cycle of disability and poverty. There is also a strong link between mental health and poverty ${ }^{12,13}$. As a consequence, one observes the violation of the rights of persons with disabilities, a greater frequency of mental health disorders among the disabled and their families, with the presence and persistence of social marginalization, rejection and exclusion. One would hope that by supporting the disabled and their families, one could help to improvetheir quality of life thereby reducing the impact of disability and mental health disorders.

Over the past ten to fifteen years the disability movement has grown in terms of the struggle to promote human rights ${ }^{13}$. In LAC it came al ongside the democratization process in many countries. Nevertheless, thelimitations of the mechanismsthat areavailablefor implementing those rights are frustrating. Poverty as well as maltreatment are indicators of the failure of achieving those human rights. One could argue that the eradication, or even reduction, of poverty and violence through the establishment of prevention programs will help to make these rights a reality. 
In recent years greater attention has been devoted to themaltreatment of women and children. Unfortunately, littleisknown about violenceagainst children and youth with disabilities. One study described by the American Academy of Pediatrics showed that children with disabilities are 1.8 times more likely to be neglect, 1.6 times more likely to be physically abused, and 2.2 times more likely to be sexually abused than children without disabilities ${ }^{33}$. A recent European study ${ }^{34}$ noted maltreatment among children with disabilities"as a taboo within a taboo, probably because the association between disability and violence is emotionally difficult to cope with". On the other hand, according to the authors, violence in families of children with disabilities is difficult to trace and to prevent. Most studies $^{33-37}$ agreed with the fact that there is inadequate and inaccurate epidemiological data available to give a clear idea of the prevalence of domestic violence against children with disabilities or special health care needs. Although the data are poor, many organizations of and for disabled persons have examples of maltreatment in their dayto-day routine, but only few of them develop a systematic approach to prevention and intervention. So, the issue of violence against children and youth with disabilities should be included on the agendas of organizationsin the disability and mental health fields.

Some authors ${ }^{34,35,37}$ believe that it is not the disability per se, that is a risk factor for maltreatment, but that it tends to be of more significance when associated with at least another risk factor, for example the level of social support. They argue that it is the interaction of several risk factors associated with the disabled individual, the family, the environment, the social and cultural circumstances and the family's economic level lead to maltreatment of the disabled child. Several researchers noted the relation between poverty and maltreatment ${ }^{34}$, even knowing that most people living in poverty do not harm their children. M elton ${ }^{38}$, in reviewing more than twelve studies of child maltreatment from the last two decades, showed that families in which maltreatment occurs have a multiplicity of serious personal, social and economic problems. In addition, many communities in which maltreated children live are themselves often dangerous and seriously disadvantaged. It should be noted that psychological variables associated with maltreatment, such as depression, low self-esteem, sense of inadequacy, impulsivity, and substanceabuse, and/or demographic factors, such as family size, economic resources, among others, are directly related to the ability of families to cope with poverty. The link between maltreatment and poverty exists but one should consider and not forget that this link is not universal. As noted above, there are many factors, independent of poverty, that areassociated with and contribute to maltreatment. Since we are focusing on disability it is important to recognize that there is a link between disability, poverty and maltreatment and that this link reflects the complexity and multidimensionality of the problem thus necessitating an eclectic, cross-disciplinary and broadbased approach to addressing the issues involving government, education, medicine, mental health, social services, employment, among others.

An agenda proposal for disability and mental health field

The design of inclusive policies is at the heart of the new disability strategy in addition to the traditional rehabilitation services, anti-discrimination measures and the provision of social safety nets. New emphasis is being given to the removal of social and environmental barriers that are preventing disabled persons from seizing opportunities for education and advancement. These policies are seen as most cost-effective because they have the potential to increase the income of disabled persons. Although the agenda is already addressing important issues, it is necessary to add other issues, according to the arguments developed in this paper.

Two issues, which are not new, but are starting to be addressed at an international level, should be included in theagenda of disability and mental health field in Latin American and Caribbean governmental and nongovernmental organizations of persons with disabilities. The systematic link between "poverty and disability" needs to be seen as a morbidity that can no longer be ignored. Also, the issue of "disability and maltreatment" should be included on the agenda. It has to be a priority of the public agenda to include the issue of poverty reduction strategiesassociated with disability and violenceprevention programs. Also it is necessary to counteract the lack of information on this multidimensional subject and search to produce statistically valid studies to providebetter visibility to this problem in LAC. The disabled population must be explicitly mentioned as "vulnerable" or "marginalized" among the other marginalized groups and must be referenced in the government plans under the strategies and programs to reduce poverty ${ }^{12,13,17-19}$.

When addressing specifically poverty reduction strategies among people with disabilities and mental health disorders the following have been sug- 
gested in recent years ${ }^{12}$ : (1) local and community level - organizations for persons with disabilities must take the struggle against poverty maintaining the focus on human rights; gather systematic prevalence information in order to providea better picture of the magnitude of this problem; strengthen the organizations' capacity to sustain poverty re duction efforts at different levels by lobbying local governmental agencies to financially invest in these efforts; (2) regional strategies - strengthen the information networks and generate knowledge related to the issues of poverty and disability; promote inter-institutional partnerships with the collaboration of government, non- government and international agencies; build in indicators to monitor the efficacy of reduction poverty programs; (3) continental strategies-createal liances between research institutes and universities to highlight and promote research on the poverty-disability cycle.

With respect to interventions to improve the quality of life for persons with disabilities it is recommended ${ }^{13}$ : a) improve the health and mobility of disabled persons - ensure infrastructure and facilities; better access to functional rehabilitation centers; develop a community-based rehabilitation program at a national level; b) promote education and training - access to special facilities within schools and universities; schooling for social inclusion, distribution of school supplies, provide scholarship for disabled persons; c) improve economic and social status - provide training and access to employment opportunities; d) combat negative stereotypes - raise awareness of positive life experiences of disabled persons; support organizations that promote the rights of persons with disabilities; develop and implement protectivelaws.

In order to develop violence prevention programs in the disability and mental health field it is necessary to define the problem, the aims to be achieved, the activities to be undertaken and the expected results. It is important to gather accurate data using uniform definitions and an accepted view and definition of maltreatment. A prevention program should monitor the process and the effects of its activities, which are not easy to predict. Organizations should start by planning internal discussions, choosing a clearly defined strategy and giving a guarantee of professional support, if necessary. Prevention involves different phases: an appreciation of risk, early detection of signs suggesting that there are stresses and dysfunction that could lead to violence, early intervention and follow up. Follow-up should adhere to specific principals: appropriate timing, flexibility according to the child and family needs, objectivity in assessing risk and protective signs and consideration of the context, the main players and their relationships. Prevention strategies should focus on reducing risk factors and strengthening protective factors and should be done utilizing a multi-disciplinary, integrated and coordinated approach, based on open, honest and rigorous communication between professionals from different disciplines (health, justice, social work, education and special education, among others). The prevention/intervention process must be formalized within the organization ${ }^{35}$.

Finally ${ }^{33,35-37}$, each prevention program and its supporting organizations should agree upon a common language, thus reducing the potential for ambiguity concerning the nature and structure of the program, theinterpretation of the effects of the program and the meaning and significance of the work. They should consider the following priorities: a) the needs of families should be met at different levels in order to enable them fulfill their fundamental role in the supporting the child's development; $b$ ) listening to and understanding the family situation should be followed by concrete support; c) to empower children, recognize their rights, explore their potentialities, enhance their skills; d) to reinforce children's communication, interaction and participation in family and nonfamily contexts; e) to encourage the development of a network made up of different public institutions, private nonprofit organizations and community/ interpersonal resourcesin thefamilies' and children's interest, with clear roles and responsibilities; f) to alert the general public to the impact and the context of the problem involving children with and without disabilities; g) to help organizations to use their political power to defend the rights of children with and without disabilities. 


\section{Collaboration}

The proposal and design of this article addressing the issue of poverty and disability were worked by $F$ Cavalcante. The final revision and the issue of disability and maltreatment were developed by $\mathrm{E}$ Goldson. The article's discussion and conclusion were done by both authors.

\section{Acknowledgements}

The authors acknowledge their research team and colleagues from Denver and Brazil, especially the ones from Claves/Ensp/Fiocruz for the opportunity of getting together during the international seminar which took place in Rio de Janeiro, Brazil which allowed this paper to be written. The authors also acknowledge M P Fiaux for hel ping with the bibliography revision.

\section{References}

1. Kempe CH, Silverman F, Steele B, Droegemueller W, Silver $\mathrm{H}$. The battered child syndrome. Journal of the American M edical Association 1962; 181:4-11.

2. Goldson E, Louch G,Washington K, Scheu H. Guidelines for the Care of the Child with Special $\mathrm{Health}$ Care Needs. Advances in Pediatrics 2006; 53:165-182.

3. Cavalcante FG, M arinho ASN, Bastos OM, M aimone MS, Deus VV, Valdene RSR, Carvalho M M, Fiaux MP, Reis LH NL, Abrantes IS, Silva M F, M achado ST, Freitas FF, Ávila AT. Violência e Direitos no campo da Deficiência: Percorrendo os Caminhos de uma Pesquisa. Relatório Técnico, Volume I. Rio de Janeiro: Claves/Ensp/Fiocruz; 2007.

4. Cavalcante FG, M arinho ASN, Bastos OM, Deus VV, Maimone MS, Carvalho M M, Fiaux MP, Valdene RSR. Diagnóstico situacional da violência contra crianças e adolescentes com deficiência em três instituições do Rio de Janeiro. Cien Saude Colet 2009; 14(1):45-56.

5. Bouillon CP, Buvinic M. Inequality, Exclusion and Poverty in Latin America and the Caribbean: Implications for Development. IDB Document from EC/IDB Seminar: Social Cohesion in Latin America and the Caribbean; 2003.

6. Engel W. Estratégias de Redução da Pobreza e da Desigualdade na América Latina e no Caribe. In: V Assembléia Plenária do Forum Interparlamentar das Américas/FIPA. Bogotá, Colômbia: Banco Interamericano de Desenvolvimento; 2006.

7. Londoño JL, Székely M. Persistent Poverty and Excess Inequality: Latin America, 1970-1995. Working paper 357. Washington, D.C.: Inter-American Development Bank; 1997.

8. Janvry A de; Sasoulet E. Growth, Poverty, and Inequality in Latin America: A causal Analysis, 1970-94. In: Conference on Social Protection and Poverty. Washington, D.C.: Inter-American Development Bank; 1999.

9. Klisberg B. América Latina: uma região de risco - pobreza, desigualdade e institucionalidade social. Brasília: UNESCO; 2002.

10. Attanasio O, Székely M. Portrait of Poor: An AssetsBased Approach. Washington, D.C.: Inter-American Development Bank; 2001.

11. Barros RP, Henriques R, M endonça R. A estabilidade inaceitável: desigualdade e pobreza no Brasil. Texto de Discussão No 800. Brasília: Ministério do Planejamento, Orçamento e Gestão/ IPEA; 2001.

12. Richler D. The Status Report on Poverty and Disability in the Americas: Voices from the Americas. United Kingdom: University of East London/Inclusion International; 2004.

13. Wolfensohn JD. Poverty reduction strategies: their importance for disability. Washington, D.C.: Disability and Development Team; 2004.

14. Costa BLD, Carneiro CBL. Implicações do enfoque da exclusão social sobre as políticas públicas: desafios para 0 desempenho governamental. Texto para discussão $n^{\circ}$ 08. Belo Horizonte: Escola de Governo da Fundação João Pinheiro; 2004.

15. Monteiro CA. A dimensão da pobreza, da desnutrição e da fome no Brasil. Estudos Avançados 1995; 9(24):195-207.

16. WHO. A29/INF/DOC3. Geneva: WHO; 1976. 
17. M etts R. Disability Issues. Trends and Recommendations for the World Bank. Washington, D.C.: World Bank; 2000.

18. Elwan E. Poverty and disability - a survey of the literature. Washington, D.C.: World Bank; 1999.

19. Yeo R. Chronic Poverty and Disability. Action on Disability and Development (ADD). M anchester: Chronic Poverty Research Centre; 2001.

20. Park J, Turnbull AP, Turnbull III HR. Impacts of Poverty on Quality of Life in Families of Children with Disabilities. Council for Exceptional Children 2002; 68(2):151-170.

21. Schalock RL. Can the concept of quality of life make a difference? In: Sahclock RL, editor. Quality of life. Volume II: application to persons with disabilities. Washington, D.C.: American Association on Mental Retardation; 1997. p. 245-267.

22. Schalock RL. Three decades of quality of life: Mental retardation in the $21^{\text {st }}$ century. In: Wehmeyer $M L$, Patton JR, editors. M ental retardation in the year 2000 Austin, Texas Pro-Ed; 2000. p. 335-356.

23. Bailey DB, M CWillian RA, Darkes LA, Hebbeler $K$, Simeonsson RJ, Spiker D, Wagner M. Family outcomes in early intervention: A framework for program evaluation and efficacy research. Exceptional Children 1998; 64:313-328.

24. Federal Child Abuse Prevention Act 42. United States Code 5106g (4); 1974.

25. Helfer R. The epidemiology of child abuse and neglect. Pediatric Annals 1984; 13:745-751.

26. National Center of Child Abuse and N eglect. National report of suspected abuse against children. Englewood: National Center of Child Abuse and N eglect; 2004.

27. Commentary. A New Definition of Children with Spe cial Health Care Needs Pediatrics 1998; 102:137-140.
28. Buvinic $M$, Morrison $A R$, Shifter $M$. Violence in the Americas: a framework for action. In: Morrison A, Biehl M, editors. Too close to home. Washington, D.C.: Interamerican Development Bank; 1999.

29. Abramovay M, Castro M G, Pinheiro LC, Lima FS, $M$ artinelli CC. Juventude, violência e vulnerabilidade social na América Latina: desafios para políticas públicas. Brasília: UNESCO/BID; 2002.

30. Westcott $H$. The abuse of disabled children: A review of the literature. Child H ealth Care Deve.1991; 17:243258.

31. Resnick MD. The Social Construction of Disability. In: Blum RW, editor. Chronic Illness in Childhood and Adolescence. Orlando, Florida: Grune and Stratton; 1984. p. 29-46.

32. Sobsey D. Violence and Abuse in the Lives of People with Disabilities: The End of Silent Acceptance. Baltimore: Paul H. Brookes Publishing Comp; 1994.

33. American Academy of Pediatrics. Assessment of Maltreatment of Children with Disabilities. Pediatrics 2001; 108(2):508-512.

34. AIAS Bologna Onlus, Fenacerci, Disability Now \& Disminuidos Físicos de Aragón. Childhood, Disability $\&$ Violence Project. Empowering disability organizations to develop prevention strategies. Full Report. European Commission: Daphne Programme; 2004.

35. Goldson E. Maltreatment among children with disabilities. Infants and Young children 2001; 13:44-54.

36. UNICEF. Violence against Disabled Children. UN Secretary Generals Report on Violence against Children Thematic Group on Violence against Disabled Children. Findings and Recommendations. Summary Report. New York: United Nations; 2005.

37. Gonzalvo GO. Qué se puede hacer para prevenir la violencia y el maltrato de los niños con discapacidades? An Pediatr (Barc) 2005; 62(2):153-157.

38. Melton GB. M andated reporting: a policy without reason. Child Abuse \& N eglect 2005; 29:9-18. 